\title{
The Identification of Knowledge and Educational Requirements for Secondary School Teachers in the Field of Health Education
}

\author{
David Pérez-Jorge1, Milagros De la Rosa Hormiga ${ }^{2}$, Pedro Álvarez Pérez ${ }^{1}$, \\ Candelaria de la Merced Díaz-González³ ${ }^{3}$ María Sandra Marrero Morales ${ }^{4}$ \\ ${ }^{1}$ Education Faculty, Universidad de La Laguna (ULL), La Laguna, Spain \\ ${ }^{2}$ Nursing Department, Education Faculty, Universidad de La Laguna (ULL), La Laguna, Spain \\ ${ }^{3}$ Servicio Canario de la Salud (Hospital Insular de Gran Canaria), Las Palmas, Spain \\ ${ }^{4}$ Faculty of Health Sciences, Universidad de Las Palmas de Gran Canaria (ULPGC), Las Palmas, Spain \\ Email: dpjorge@ull.es
}

Received 15 April 2015; accepted 19 May 2015; published 22 May 2015

Copyright (C) 2015 by authors and Scientific Research Publishing Inc.

This work is licensed under the Creative Commons Attribution International License (CC BY). http://creativecommons.org/licenses/by/4.0/

(c) (i) Open Access

\begin{abstract}
The present society requires the individuals to have the ability to adapt to changes, as an instrument to achieve the full integration of all of its members. Problems related to health care, both individual and collective, are considered as an essential aspect in the set of social values. Thus, the value attributed to health and wellbeing is a relevant aspect in that set of social values. It can be stated that health education should be a guiding principle in the integral education of the person. In this sense, educational institutions should act as providing basic resources which allow individuals their full development, without forgetting health care and promotion through the development of educational programmes in the field of health. This research shows the design of an instrument for assessing the teachers' degree of knowledge as regards school health and their attitude and predisposition to learn to solve situations related to health problems in the school context.
\end{abstract}

\section{Keywords}

Health Care Education, Secondary Schools, School Teachers, Instrument

\section{Introduction}

Educational centers, as settings of socializing the individual, are essential to the development and socialization

How to cite this paper: Pérez-Jorge, D. et al. (2015). The Identification of Knowledge and Educational Requirements for Secondary School Teachers in the Field of Health Education. Psychology, 6, 773-781. 
of children from early childhood. Therefore, they fulfill a very important task because they promote both behavioral development and personal and social values of the individual.

When health is considered not only as the absence of illness but also as a complete physical, mental and social wellbeing (Organización Mundial de la Salud, 1948), we can state that the achievement of positive educational results, considered as a whole, is closely related to the achievement of optimal health levels in the educational community. As regards this reality, those schools, which incorporate health promotion as an integral component in their educational approach, are establishing the bases which let them get both educational objectives with academic character and objectives centred on the integral development of the student. In this sense, health education and its treatment from the educational context suppose an opportunity to get the promotion and integral development of students.

Curricular implementation in health education constitutes one of the key strategies an educational institution has, not only to increase health levels in students, but also to improve the internal environment of the school, optimize its management processes and reach better educational results both in the academic field and as regards the prevention of unhealthy patterns.

\section{Main Problems in the Field of Educational Health}

Children and adolescents get sick or are healthy depending on a series of elements and factors which can be both negative and positive, taking into account the habits or knowledge they have about health. These elements are the biological, psychological and social determinants about health. The way in which they interact with each other and affect children are determinants in the explanation of the situation or health problems they can have. We will be capable of preventing or changing these problems if we are able to identify them and specify the effect on the individual's health.

The main characteristics of the comprehensive approach to health determinants show that one of the most important aspects in intervention is the way in which students and adults construct their idea of health and their thinking on health and illness, from a collective and social view and from the necessity to create reflexive processes in order to direct those decisions related to the promotion of better health conditions. In this sense, we consider that it is fundamental to help teachers promote better health conditions in children, adolescents, parents and other people to make them decide which is the best way to keep or improve their health.

The programmes related to health promotion and education represent a strategy which tries to focus on the modification of health determinants, considering the present health problems in the educational community.

- According to the data published in the last studies as regards health and performed in the student population at a national level, there exists a series of problems related to health which reveal an important lack as regards the child's educational health. These results have attempted to redirect the situation taking into account health intervention, where some sensitization and prevention programmes have been developed. Nevertheless, these data show alarming figures, as it can be observed in some studies supported by OMS-OPS (2010), Bureau Asociación Española Contra el Cáncer (2010), and Plan Nacional de Drogas (2007).

- Spain has become the fourth country in the European Union with the greatest number of overweight children, showing an obesity profile of $16.1 \%$ in children between 6 and 12 years of age, a figure only exceeded by Italy, Malta and Greece.

- The prevalence of anorexia nervosa has been estimated between $0.5 \%$ and $3 \%$ in the adolescent and women group. These figures are duplicated when they include "healthy" adolescents with abnormal eating behaviours or abnormal concern for their body weight.

- Only 7.5\% of Spanish children have a varied and balanced breakfast.

- $12 \%$ of Spanish children do not usually have breakfast.

- 33\% of Spanish people between 16 and 24 years of age smoke and from 50\% to 70\% of children and adolescents live in a smoking environment according to a report published by Bureau Asociación Española Contra el Cáncer (2010).

- $12.5 \%$ of boys and $16.9 \%$ of girls smoke daily.

- According to Plan Nacional de Drogas (2007), 75\% of students between 14 and 18 years of age have consumed alcoholic drinks in the last year, overall at the weekends. Moreover, $38 \%$ of children between 16 and 18 years of age celebrate drinking in the street.

- According to a report published by Plan Nacional de Drogas (2007), 2.2\% of Spanish adolescents between 14 and 18 years of age present a problematic consumption of cannabis.

- $15 \%$ of adolescents between 18 and 25 years of age provoke, at least, a traffic accident a year, damages in 
which 600 people die and more than one hundred people become disabled.

- The main fears of Spanish children are unwanted pregnancies $(87 \%)$, over sexually transmitted diseases $(43 \%)$ and HIV $(24 \%)$.

The results of these studies have led the Council of Europe to insist urgently on the necessity to strengthen in educational institutions the acquisition of knowledge in order to promote the development of children to make them choose a healthy lifestyle.

\section{Systematization and Approach to the Problem}

Health education is a tool of social transformation. As it happens in other social dynamics situations, the significance of this phenomenon results from the social relations and representations (Cordero \& Rodríguez, 2008).

The fact of implementing health teaching in schools can be considered as a strategy oriented to favor the individuals' development. Therefore, health education has to be regarded as an essential subject in the student's curriculum. Its aim is to favour his/her development through the different curricular areas and throughout all educational stages.

Therefore, in this study we attempt to evaluate the degree of knowledge and the measures taken to introduce health education programmes in schools. In summary, the problem of investigation can be synthesized through the following questions:

- What level of knowledge and attitudes do teachers have about Health in the school context?

- What is the teachers' opinion about Health Education?

- What is the teachers' competence level to face and cope with situations related to emergencies in the school context?

General objective was to design an instrument to evaluate the teachers' degree of knowledge as regards school health and their attitude and predisposition to learn to solve situations related to health problems in the school context.

\section{Method}

This research was performed in two schools in Tenerife with a sample of teachers who participated voluntarily, giving their opinions as regards their knowledge and attitudes in the field of health education. The selection of the centers was carried out through a purposive non-randomized sampling procedure. The educational centers were chosen arbitrarily from the group of centers offered and linked through a collaboration agreement to the University of La Laguna in the academic course 2013-14.

\section{Characteristics of the Teachers' Sample}

The sample of teachers was made up of 59 teachers $(52.5 \% \mathrm{~N}=31$, from public education centers and $47.5 \% \mathrm{~N}$ $=28$, from one private teaching center). $44.1 \%$ were male teachers and $55.9 \%$ female teachers. The age range was $[25-50]$ and the mean age was the 42.5 .

Teachers taught mainly at higher education levels (Compulsory Secondary Education, $(54.2 \% \mathrm{~N}=32$ ) and high school studies $(45.8 \% \mathrm{~N}=27)$. As regards the level of education, a prevalence of graduates $44.1 \% \mathrm{~N}=26$ was observed, compared to $47.5 \% \mathrm{~N}=28$ of postgraduates or $8.5 \% \mathrm{~N}=5$ of university experts.

As regards beliefs and health habits, it was stated that all the teachers defined themselves as healthy individuals who considered relevant to develop healthy habits in children from childhood (100\%). All of them had experiences with the main disorders and health problems at school level (see Figure 1).

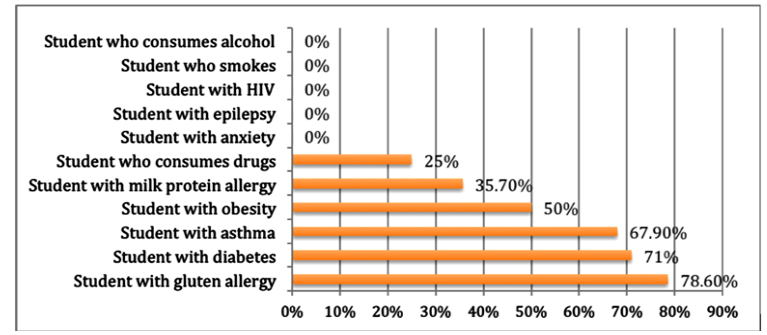

Figure 1. Teachers' experience as regards the main illnesses/disorders and addictions in schools. 


\section{Instruments}

The instruments which are proposed to evaluate teachers' attitudes and knowledge in the field of health education was one questionnaire prepared for this study taking into account the most common situations about school health and emergencies.

The questionnaires used were ad hoc tests adapted to the objective of the study. The "Questionnaire about attitudes and knowledge as regards health in the school context" (CACOSA) was performed taking as a basis the Healthy Child Programme conducted by the Canary Islands Health Service (2007).

This questionnaire (CACOSA) was finally made up of 41 items. The answers of the different items in the scale reflected the degree of agreement as regards the opinions related to prevention of addictive behavior, food and nutrition, prevention and attention before risk situations and the most frequent illnesses in school children, accidents and emergencies in the school context, and teachers' predisposition and attitude. Each item was valued punctuating from 1 (the lowest level of agreement) to 6 (the highest level of agreement).

\section{Data Analysis}

Taking into account the objective of this study, an analysis of both the reliability and the underlying structure of CACOSA was performed.

\section{CACOSA Reliability Analysis}

In order to perform the reliability analysis, Cronbach's Alpha internal consistency coefficient has been used since we consider that our scale was made up of homogeneous elements which measured the same characteristic and its internal consistency could be evaluated through the average correlation among the different elements. We performed the same procedure as the one we applied in a previous study (De la Rosa Hormiga, Pérez-Jorge, Díaz-González, Rodríguez Jimenez, \& Marrero Morales, 2015). The procedure was applied to 41 items in the teachers' questionnaires and a value of 0.82 was obtained, indicating a high consistency of the scale.

\section{Analysis of the Underlying Dimensions of CACOSA}

An analysis of the main components was performed to determine the underlying structure of both questionnaires. This analysis was carried out with the aim of reducing the items to the empirical dimensions taken from the analysis in order to interpret the sense of the answers obtained better.

AVARIMAX rotation was used to produce an orthogonal structure of the results obtained.

The analysis was applied to a valid $\mathrm{N}$ of 59 teachers. The index KMO of sampling adequateness obtained an acceptable value of 0.757 and enabled us to proceed with factorization. On the other hand, Bartlett test of sphericity proved to be significant $\left(\chi^{2}=2536.2,1238 \mathrm{gl}, p<0.000\right)$. Therefore, we determined the factor analysis based on correlation matrix. After some tests, we decided to opt for 5 components which explained a $53.11 \%$ of the variance.

The composition of each factor (structure coefficient), the variance percentage which each factor explained, and their own values are shown in Tables 1-5.

This component collects items on perception and knowledge that the teacher has certain behaviors considered addictive (Table 1).

This component is formed by items which reflect the teachers' perception and knowledge about eating habits (Table 2).

This component refers to items related to common illnesses in schools and how to avoid risks related to health in the school context (Table 3).

This factor comprises those items related to the way of acting before accidents and emergency situations in the school context (Table 4).

This factor collects items about the teachers' opinion and general attitude about health education (Table 5). After the analysis of the different items of CACOSA, the following five major factors have been obtained:

Factor 1: Prevention of addictive behavior.

Factor 2: Food and nutrition. Prevention of children obesity.

Factor 3: Prevention and attention before risk situations and the most frequent illnesses in school children. 
Table 1. Prevention of addictive behavior.

\begin{tabular}{cc}
\hline Item (number) & Value \\
\hline Drug consumption in schools is common (9) & 0.767 \\
When a student consumes cannabis, the signs can be identified (10) & 0.746 \\
My students know the side effects of drugs (12) & 0.633 \\
I think that the use of social networks for many hours a day can be considered as an addiction (14) & 0.562 \\
Intrinsic value $=13.353 \%$ rotation variance $=13.661$ &
\end{tabular}

Table 2. Food and nutrition. Children obesity prevention.

Item (number)
Pasta and bread are protein rich foods (1)
A child with celiac disease can eat gofio wheat (2)
Fats called "trans or bad" are overall contained in poultry meat (5)
Children suffering from milk protein allergies can drink milk and goat yoghourt (6)
The only symptom in anorexia is the extreme thinness (7)
The only risk factor which causes obesity in childhood is the high intake of food (8)
Intrinsic value $=5.760 \%$ rotation variance $=12.236$
0.698

Table 3. Prevention and attention before risk situations and most frequent illnesses in school-age children.

\begin{tabular}{|c|c|}
\hline Item (number) & Value \\
\hline I know how to react when a child is diabetic and suffers from hypoglycaemia (3) & 0.703 \\
\hline A diabetic child can carry his/her insulin in his/her pencil box (4) & 0.676 \\
\hline I understand that when a child is seropositive he/she has AIDS (15) & 0.622 \\
\hline All barrier contraceptive methods prevent us from sexually transmitted diseases (STD) (16) & 0.611 \\
\hline Some of the most common parasomnias are nocturnal enuresis and sonambulism (17) & 0.524 \\
\hline When a child has an epileptic seizure, he/she can normally feel sleepy and disoriented (19) & 0.502 \\
\hline An asthmatic child can practice exercise and sports (20) & 0.492 \\
\hline Intrinsic value $=4.060 \%$ rotation variance $=9.634$ & \\
\hline
\end{tabular}

\section{Table 4. Accidents and emergencies in the school context.}

Item (number)
In cases of eye injuries, you should rub the affected area and eliminate the causative agent $(21)$
Heimlich maneuver can only be performed when there is a digestion cut (22)
Cardiac massage can only be performed in a cardiorespiratory arrest when the 112 emergency service arrives (23)
I think that a child has suffered a cardiorespiratory arrest if he/she is unconscious, breathes and has pulse (24)
During an epileptic seizure, anal medication can never be administered (25)
Intrinsic value $=3.630 \%$ rotation variance $=8.957$
0.523


Table 5. Teachers' predisposition and attitude.

\begin{tabular}{|c|c|}
\hline Item (number) & Value \\
\hline In my courses I tell the students about the negative effects of tobacco and drug consumption (11) & 0.704 \\
\hline I know what to do if I see one of my students consuming cannabis (13) & 0.606 \\
\hline I think I should be properly informed about those pathologies which can be suffered by the students (18) & 0.567 \\
\hline $\begin{array}{l}\text { I am very interested in teaching my students how to respond to emergencies which threaten the life of one of their classmates } \\
\text { (26) }\end{array}$ & 0.489 \\
\hline I think I am properly trained and prepared to deal with an emergency (27) & 0.471 \\
\hline I think that educational centers should deal with health education in a cross-sectional manner (28) & 0.468 \\
\hline Taking into account your teaching experience, do you think that health education is not adequately taught in schools? (29) & 0.453 \\
\hline I would like to receive more information about school health (30) & 0.450 \\
\hline I think all the information about health is useful (31) & 0.443 \\
\hline I am very satisfied when I solve an emergency at school (32) & 0.441 \\
\hline I am very interested in emergency issues in the school context (33) & 0.439 \\
\hline I have received appropriate training about emergencies in the school context (34) & 0.431 \\
\hline I think that teachers are not interested in health issues in the school context (35) & 0.423 \\
\hline I enjoy learning things to improve my students' health (36) & 0.416 \\
\hline Students usually ask questions about health (37) & 0.409 \\
\hline I have promoted health education in my students (38) & 0.401 \\
\hline Knowledge about health education is useful for daily life (39) & 0.397 \\
\hline When I have a doubt I try to solve it looking for (40) & 0.392 \\
\hline I think that each educational center should have a health professional (41) & 0.374 \\
\hline Intrinsic value $=3.081 \%$ rotation value $=8.623$ & \\
\hline
\end{tabular}

Factor 4: Accidents and emergencies in the school context.

Factor 5: Teachers' predisposition and attitude.

\section{Conclusion}

The objective of this study was to design and verify the quality of an instrument proposed in order to evaluate the degree of knowledge that teachers showed about health in schools and the attitude and predisposition to learn to solve situations related to health problems in the school context. The fact of analyzing the situation of secondary school teachers as regards the main aspects of health education has let us observe the degree of knowledge and the protocols for action used by teachers before school situations related to their students' health. We consider that the design of a useful instrument to analyze these aspects is of great importance to detect both the teachers' formative needs and their lack of qualification in the field of health education.

The internal consistency of the instrument designed has proved to be satisfactory. The 5 subscales obtained have shown reliability values over 0.80 , being the total value of the test of 0.82 . None of the 41 items in the test designed were problematic.

It can be stated that, after studying CACOSA metric properties, this instrument is both reliable and adequate. Therefore, it can be recommended as a tool to examine the teachers' knowledge about health education and their attitude and predisposition to educate on health issues. Thus, the validity of the evidence and its internal struc- 
ture appear to be adequate as regards its content (validated by experts). As regards the last aspect, the factors obtained have been coherent if we take into account the theoretical dimensions proposed by the Healthy Child Programme (Servicio Canario de Salud, 2007).

The data reduction procedure (factorization) used has proved to be adequate and coherent as regards the dimensions given. Therefore, we propose, in future analyses and as regards the interpretation of results, to consider these dimensions due to their theoretical value and consistency.

\section{References}

Bureau Asociación Española Contra el Cáncer (2010). Documenting Electronic Sources on the Internet. https://www.aecc.es/INVESTIGACION/OBSERVATORIODELCANCER/ESTUDIOSREALIZADOS/Paginas/Conocimi entosycreencias.aspx

Cordero, X., \& Rodríguez, X. (2008). Reflexiones sobre educación sexual desde una perspectiva holistica. México: Revista Iberoamericana, Diccionario de la Ciencia de la Educación, Editorial Santillana.

De la Rosa Hormiga, M., Pérez-Jorge, D., Díaz-González, C. M., Rodríguez Jiménez, M. C., \& Marrero Morales, M. S. (2015). An Approach to Obligatory Secondary Education Teachers' Perception Regarding Orientation Processes and Response to Diversity. Psychology, 6, 606-612. http://dx.doi.org/10.4236/psych.2015.65058

OMS-OPS (2010). Promoción de la salud sexual. Recomendaciones para la acción. Guatemala: Actas de una Reunión de Consulta convocada por Organización Panamericana de la Salud (OPS), Organización Mundial de la Salud (OMS), en colaboración la Asociación Mundial de Sexología. http://www.bvsde.paho.org/bvsacd/cd67/salud sexual.pdf.

Organización Mundial de la Salud (1948). Constitución de la Organización Mundial de la Salud. http://apps.who.int/gb/bd/PDF/bd47/SP/constitucion-sp.pdf?ua=1

Plan Nacional de Drogas (2007). Documenting Electronic Sources on the Internet. http://www.pnsd.msc.es/Categoria2/publica/pdf/memo2007.pdf

Servicio Canario de Salud (2007). Healthy Child Programme. Consejería de Sanidad (2nd ed.). Canarias: Consejería de Sanidad Dirección General de Programas Asistenciales, Servicio de Atención Primaria, Planificación y Evaluación. 
Questionnaire about Knowledge and Attitude of Teachers about Health in the School Context

\section{CACOSA (2014)}

\section{Identification data}

Educational Center:

Age:

Gender: $\square$ male $\square$ female

Studies completed

Years of teaching experience Years of teaching experience in this center

Course in which you teach (if you teach in several courses, write only the course in which you have the greatest number of teaching hours a week)

Subject you teach (if you teach several subjects, select that in which you have the greatest number of teaching hours a week)

Do you think you are a healthy person? $\square$ Yes $\square$ No

Do you think it is important to have healthy habits from childhood? $\square$ Yes $\quad \square$ No

During my teaching activity I have had students with the following illnesses/disorders or addictions: (mark the affirmative answers with an $\mathrm{X}$ )
Diabetes $\square$ Gluten Allergy
Seropositivity (HIV)
$\square$ Asthma
$\square$ Milk protein allergy
$\square$ Others
Obesity
Drug consumption

Read each sentence or statement taking into account your level of agreement. If you totally agree, you should select option 6 and if you totally disagree you should select option 1. Be sure to answer all the questions although you are not completely sure about the best answer.

1. Pasta and bread are protein-rich foods.

2. A child with celiac disease can eat gofio wheat.

3. I know how to react when a diabetic child suffers from hypoglycaemia.

4. A diabetic child can carry his/her insulin in his/her pencil box.

5. Fats called "trans or bad" are overall contained in poultry meat.

6. Children suffering from milk protein allergies can drink milk and goat yoghourt.

7. The only symptom in anorexia is the extreme thinness.

8. The only risk factor which causes obesity in childhood is the high intake of food.

9. Drug consumption in schools is common.

10. I know how to identify signs when a student consumes cannabis.

11. In my courses I tell the students about the negative effects of tobacco and drug consumption.

12. My students know the side effects of drugs.

13. I know what to do if I see one of my students consuming cannabis.

14. I think that the use of social networks for many hours a day can be considered as an addiction. 
15. I understand that when a child is seropositive he/she has AIDS.

16. All barrier contraceptive methods (spermicides, condoms, sponges, diaphragms, cervical caps, etc.) prevent us from sexually transmitted diseases. (STD)

17. Some of the most common parasomnias are nocturnal enuresis and sonambulism.

18. I think I should be properly informed about those pathologies which can be suffered by the students

19. When a child has an epileptic seizure, he/she can normally feel sleepy and disoriented.

20. An asthmatic child can practice exercise and sports.

21. In cases of eye injuries, you should rub the affected area and eliminate the causative agent.

22. Heimlich maneuver can only be performed when there is a digestion cut.

23. Cardiac massage can only be performed in a cardiorespiratory arrest when the 112 emergency service arrives.

24. I think that a child has suffered a cardiorespiratory arrest if he/she is unconscious, breathes and has pulse.

25. During an epileptic seizure, anal medication can never be administered.

26. I am very interested in teaching my students how to respond to emergencies which threaten the life of one of their classmates.

27. I think I am properly trained and prepared to deal with an emergency.

28. I think that educational centers should deal with health education in a cross-sectional manner.

29. Taking into account your teaching experience, do you think that health education is not adequately taught in schools?

30. I would like to receive more information about school health.

31. I think all the information about health is useful.

32. I am very satisfied when I solve an emergency at school.

33. I am very interested in emergency issues in the school context.

34. I have received appropriate training about emergencies in the school context.

35. I think that teachers are not interested in health issues in the school context.

36. I enjoy learning things to improve my students' health.

37. Students usually ask questions about health.

38. I have promoted health education in my students.

39. Knowledge about health education is useful for daily life.

40. When I have a doubt I try to solve it looking for information.

41. I think that each educational center should have a health professional. 